NASA Technical Memorandum 107216

\title{
Calculation of Tip Clearance Effects in a Transonic Compressor Rotor
}

Rodrick V. Chima

Lewis Research Center

Cleveland, Ohio

Prepared for the

41 st Gas Turbine and Aeroengine Congress

sponsored by the American Society of Mechanical Engineers

Birmingham, United Kingdom, June 10-13, 1996

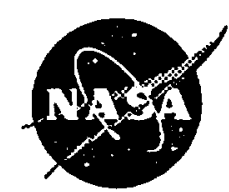

National Aeronautics and

Space Administration 



\title{
CALCULATION OF TIP CLEARANCE EFFECTS IN A TRANSONIC COMPRESSOR ROTOR
}

\author{
Rodrick V. Chima \\ NASA Lewis Research Center \\ Cleveland, Ohio 44135 USA
}

\begin{abstract}
The flow through the tip clearance region of a transonic compressor rotor (NASA rotor 37) was computed and compared to aerodynamic probe and laser anemometer data. Tip clearance effects were modeled both by gridding the clearance gap and by using a simple periodicity model across the ungridded gap. The simple model was run with both the full gap height, and with half the gap height to simulate a vena-contracta effect. Comparisons between computed and measured performance maps and downstream profiles were used to validate the models and to assess the effects of gap height on the simple clearance model. Recommendations were made concerning the use of the simple clearance model. Detailed comparisons were made between the gridded clearance gap solution and the laser anemometer data near the tip at two operating points. The computed results agreed fairly well with the data but overpredicted the extent of the casing separation and underpredicted the wake decay rate. The computations were then used to describe the interaction of the tip vortex, the passage shock, and the casing boundary layer.
\end{abstract}

\section{INTRODUCTION}

It is well known that tip clearance flows can reduce the pressure rise, flow range, and efficiency of turbomachinery. Smith and Cumpsty [16] have shown a 23 percent drop in maximum pressure rise and a 15 percent increase in flow coefficient at stall in a large, low speed compressor as the tip clearance was increased from 1 to 6 percent of chord. Wisler [23] has shown a 1.5 point drop in efficiency of a low speed compressor when the tip clearance was doubled. Yet the details of tip clearance flows are not well understood. Storer and Cumpsty, for example, suggest that most of the loss often attributed to tip clearance effects are probably due to other causes [19].

Several analytic models of tip clearance flows have been developed. Chen et al. [4] developed a model that predicts the trajectory of the clearance vortex. Denton [10] and Storer and Cumpsty [19] have developed models that estimate tip clearance losses based on mixing of the clearance jet with the freestream flow. The analytical models all assume inviscid, incompressible flow, infinitely thin blades, and that the pressure difference across the blade tip drives the flow. They also assume that a vena-contracta effect causes separation at the edge of the blade that must be modeled with an empirical discharge coefficient. None of the models consider the effects of the clearance flow on the endwall boundary layers or on the stall point.

Tip clearance flows have also been studied computationally. Dawes [9] computed clearance flows in a transonic compressor by rounding the blade tip such that an $\mathrm{H}$-type grid could be distorted to fill in the gap over the blade. Kirtley, et al. [12] proposed a simple clearance model that assumes that the flow is tangentially-perjodic across a non-gridded region above the blade. The model is exact for infinitely thin blades. Adamczyk et al. [2] used Kirtley's model to examine the role of tip clearance flows in high-speed fan stall. They calibrated the model to simulate the vena-contracta effect by reducing the size of the gap until the calculations matched an experimentally-measured stall point. Suder and Celestina [21] examined tip clearance flows in a transonic compressor rotor at several operating points. They compared calculations made using Kirtley's clearance model with laser anemometer data made near the tip of the rotor. Ameri and Steinthorsson [1] used a fine multiblock grid in the clearance gap over a low-speed turbine rotor to compute the edge separation in detail.

In the present work the flow through the tip clearance region of a transonic compressor rotor, designated NASA rotor 37, was computed using three clearance models. The first clearance model used a fine $\mathrm{O}$ type grid in the clearance region and the author's SWIFT multiblock turbomachinery analysis code to resolve the details of the clearance flow. These computations were originally made for the ASME code assessment "blind" test case presented at the ASME/GTI 39th International Gas Turbine Conference held in The Hague in June of 1994. The results of the blind test case have not yet been published, but a brief overview was given in [20]. Details of the SWIFT code and the predictions required for the test case will be published elsewhere. The other two models applied Kirtley's simple periodicity model over either the full gap height or a reduced gap height to simulate a vena-contract 
effect. The three models were compared to each other and to experimental performance maps and aerodynamic probe data to assess the effects of the reduced gap height on the predicted performance.

There were three objectives to the present work:

1. To determine the accuracy of the simple periodicity clearance model for overall performance calculations by comparing it to the more detailed multiblock model. The effects of reducing the gap height to simulate a vena-contracta effect were also studied.

2. To validate the multiblock model in the clearance region through detailed comparisons to experimental data and to the analytic clearance model described in [4]. The blind test case did not require comparisons in the clearance region.

3. To investigate the interaction of the shock, the clearance vortex, and the casing boundary layer at operating points near peak efficiency and near stall using the multiblock calculations.

\section{TEST COMPRESSOR AND EXPERIMENTAL MEASUREMENTS}

A low aspect ratio transonic inlet rotor for a core compressor, designated NASA rotor 37 , was used for the present study. The rotor was originally designed and tested at NASA Lewis Research Center in the late 1970's by Reid and Moore [14 and 15]. The rotor has a design pressure ratio of 2.106 at a mass flow of $20.19 \mathrm{~kg} / \mathrm{sec}$, with a measured choking mass flow of $20.93 \mathrm{~kg} / \mathrm{sec}$. The rotor has 36 multiple-circulararc blades with a hub-tip ratio of 0.7 , an aspect ratio of 1.19 , and a tip solidity of 1.288 . The running tip clearance was estimated to be 0.0356 $\mathrm{cm}(0.45$ percent span) for the blind test case using both touch probe and rub probe measurements. It has since been revised to $0.0400 \mathrm{~cm}$ [21]. The design wheel speed is $17,188.7 \mathrm{rpm}$, giving a nominal tip speed of $454 \mathrm{~m} / \mathrm{s}$.

For the blind test case the isolated rotor was tested in a singlestage compressor facility at NASA Lewis. A brief description of the test facility and laser anemometer system was given by Suder, et al. in [21 and 22]. Mass flow was measured using a calibrated orifice plate far upstream of the rotor. Radial distributions of static and total pressure, total temperature, and flow angle were measured at two axial stations designated stations 1 and 4 . Using the blade hub leading edge as the origin, station 1 was at $z=-4.19 \mathrm{~cm}$ and station 4 was at $z=10.19 \mathrm{~cm}$. In the present work the inlet and exit of the computational grid were chosen to coincide with stations 1 and 4. Data at two other axial stations are also referenced here. Station 2 was located inside the passage 0.2 chords downstream of the leading edge, and station 3 was just downstream of the trailing edge at $z=4.57 \mathrm{~cm}$.

A laser fringe anemometer system was used to obtain detailed velocity measurements throughout the flow field. A two-color system gave simultaneous measurements of the axial and tangential components. Velocity measurements were made in 184 windows across each of the 36 passages as the blades passed by. Approximately 300-400 measurements were made at each $(x, r)$ location and then ensembleaveraged to give results for an average passage. Measurements were made at $30,50,70,90$, and 95 percent span, and at axial intervals of about 5 percent chord. In the present work comparisons were only made at 95 percent span.

\section{SWIFT Multiblock Analysis Code}

Calculations were made using the SWIFT turbomachinery analysis code, which is a multiblock version of the single block RVC3D code described in [5 and 7]. The SWIFT code solves the Navier-Stokes and energy equations on body-fitted grids using an explicit finite-difference scheme. It includes viscous terms in the blade-to-blade and hub-to-tip directions, but neglects them in the streamwise direction using the thinlayer approximation.

The turbulent viscosity was modeled using the Baldwin-Lomax turbulence model [3], implemented as described in [6]. The standard model constants were replaced by $C_{c p}=1.216$ and $C_{K l e b}=0.646$, which were shown in [6] to give better agreement with the standard Cebeci-Smith model. Hub and casing profiles were assumed to be fully turbulent, but the blade boundary layer was allowed to transition using the model proposed by Baldwin and Lomax. The effects of transition on this rotor are discussed in [22].

Storer and Cumpsty have noted that tip clearance effects seem to be calculated fairly accurately with Navier-Stokes codes using coarse grids and unsophisticated turbulence models in the clearance region [18]. In the present work; however, some early calculations were made using a turbulent viscosity model for fully-developed duct flow across the clearance gap. Stall was predicted at a very high a flow rate using this model. The model was replaced with the Baldwin-Lomax model adapted to the clearance region. The inner formulation was used near the blade tip and the casing, and a constant outer turbulent viscosity was used across the rest of the gap. For the outer formulation $f_{\max }$ was taken as the maximum of the function $f$ across the entire gap, and $y_{\max }$ was taken as the distance to the nearest of the tip or casing walls. As will be shown later the new model predicted the stall point fairly accurately, suggesting that some aspects of the clearance flow may be strongly affected by the turbulence model. Unfortunately, the original results were discarded and the reasons for its poor performance were not determined.

Boundary conditions were specified as follows: At the inlet, $T_{0}$ was set to a constant and $P_{0}$ profiles were specified to match equilibrium turbulent velocity profiles. Inlet boundary layer thickness were set to 10 percent span at both the hub and the tip based on limited experimental data. Note that the inlet casing boundary layer was 45 times larger than the clearance gap. At the exit the hub static pressure ratio was specified and simple radial equilibrium was solved. At the walls, no-slip boundary conditions were used and pressure and temperature gradients were set to zero (adiabatic walls.)

An explicit, multistage Runge-Kutta scheme [11] was used to solve the flow equations. Physical and artificial dissipation terms were computed only at the first stage for efficiency. Conservative secondand fourth-difference artificial dissipation terms were added to capture shocks and to control point decoupling. Eigenvalue scaling as described in [13] was used to scale the artificial dissipation directionally on the highly stretched grids. The artificial dissipation was also reduced linearly with grid index near solid surfaces (typically by a factor of 0.04 at the wall) to minimize effects on boundary layers. A spatially-varying time step and implicit residual smoothing were used to accelerate convergence to a steady state, and Eigenvalue scaling was used to minimize the implicit smoothing coefficients at each point in each direction. All calculations were run with a four-stage Runge-Kutta scheme at a Courant number of 5.6.

\section{COMPUTATIONAL GRIDS}

A multiblock grid was generated using the TCGRID turbomachinery grid code, which is described briefly in [7]. The code generates C- 


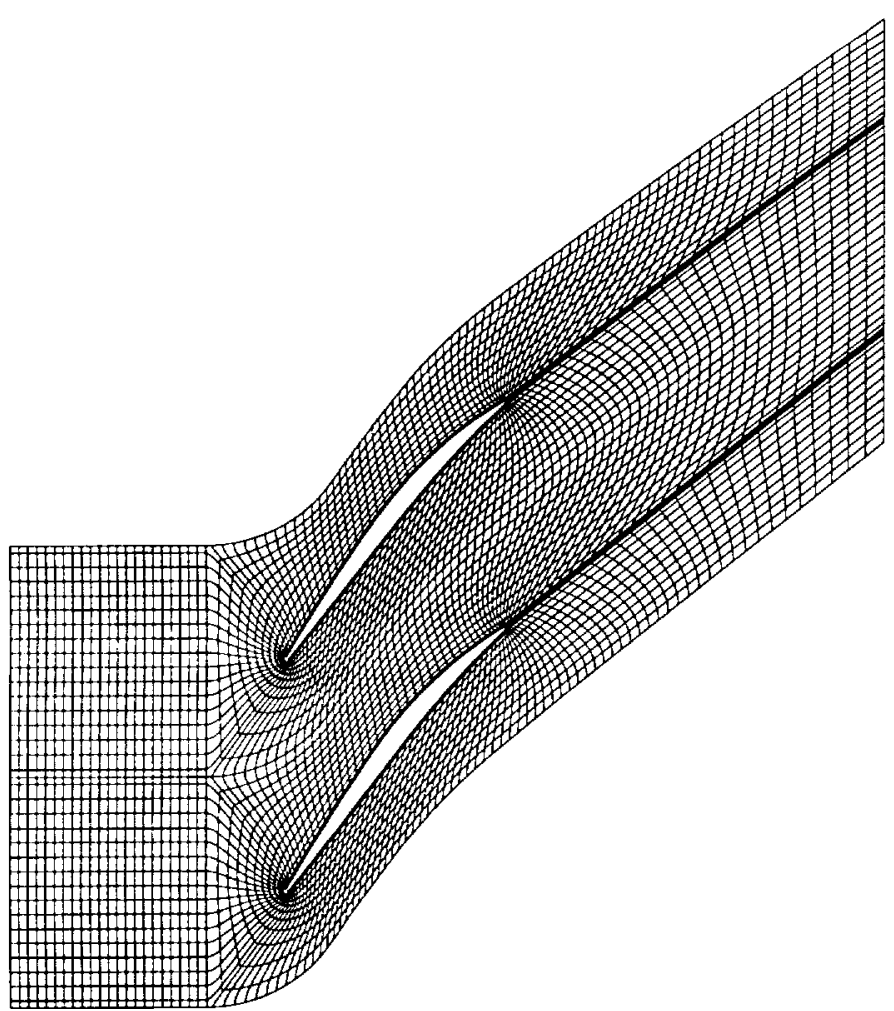

Fig. 1. H-C grid at 70 percent span. Grid lines have been omitted for clarity.

type blade-to-blade grids at a few spanwise locations using an elliptic grid generator developed by Sorenson [17]. The C-grids are reclustered spanwise using a hyperbolic tangent clustering function. Transfinite interpolation is used to generate an $\mathrm{H}$-grid ahead of the blade, and an algebraic $\mathrm{O}$-grid is generated to fill the hole in the $\mathrm{C}$-grid in the tip clearance region above the blade. Each grid overlaps its neighbor by one point. Grid generation takes about 30 seconds on a Cray C-90.

The $\mathrm{C}$-grid had 319 points around the blade, with 60 points along each side of the wake and 199 points on the blade surface. Grid spacing at the blade and endwalls was $4 \times 10^{-4} \mathrm{~cm}$, giving $\mathrm{y}^{+}=2$ to 4 at the surface. There were 46 points from the blade to the periodic boundary, or effectively 89 points blade-to-blade. There were 63 points spanwise with 13 points across the clearance gap. The C-grid had a total of 924,462 points.

The $\mathrm{H}$-grid ahead of the blade had 45 points streamwise, 35 points blade-to-blade and 63 points spanwise, for a total of 99,225 points. The blade-to-blade $\mathrm{H}$-C-grid at 70 percent span is shown in figure 1 , where points have been omitted for clarity.

The O-grid in the tip clearance region is shown in figure 2. It had 199 points in the O-direction, 13 points from the mean camber line to the blade surface, and 13 points across the gap, for a total of 33,631 points. The gap was specified as $0.0356 \mathrm{~cm}$ as measured experimentally. Although the gap was only 0.45 percent of the span it was 89 times the grid spacing at the casing, so the $\mathrm{O}$-grid was highly stretched across the clearance gap. There were $1,057,318$ points in the full multiblock grid.

A single-block C-type grid was also generated using TCGRID for use with the simple tip clearance model. The single-block grid was

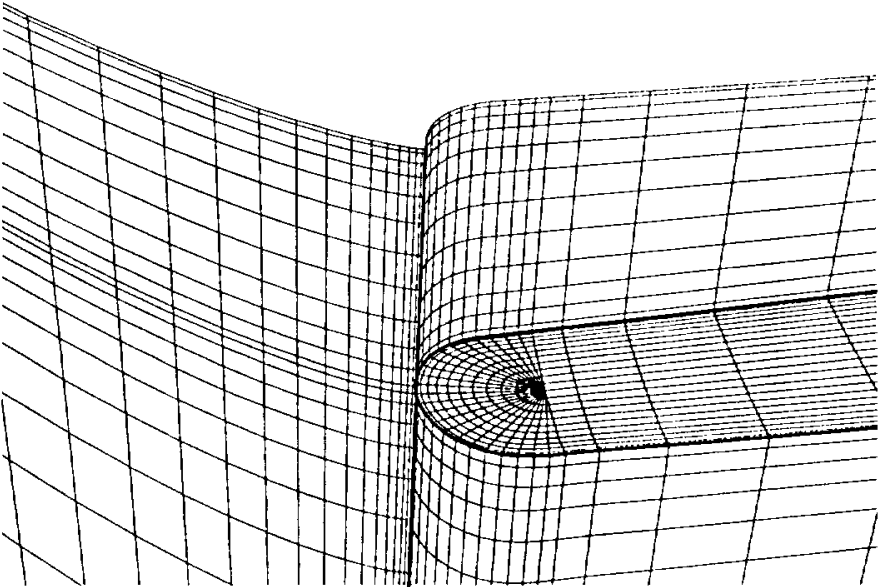

Fig. 2. Tip clearance grid near the leading edge.

identical to the C-part of the multiblock grid except that the number of spanwise points was reduced from 63 to 51 by deleting the points in the clearance gap and reclustering the remaining points to the casing. This left nine points across the gap. The single-block C-grid was also stretched about one-half pitch further upstream than the C-part of the multiblock grid, but not as far upstream as the $\mathrm{H}$-grid. There were 748,374 points in the single block grid.

\section{COMPUTATIONAL DETAILS}

Multiblock calculations were run on the Cray C-90 computer vonneuman at NASA Ames Research Center, under support of the Numerical Aerodynamic Simulation (NAS) Project Office. A few calculations were also run on the Cray Y-MP at NASA Lewis Research Center. The C-90 was approximately 2.2 times faster than the Y-MP.

All grid and solution arrays were stored on the Cray solid state storage device (SSD). The code was dimensioned to hold the largest grid, here the C-grid, in core memory. Asynchronous I/O was used on the Cray to move the grid and solution arrays between the core memory used by the solver and the SSD. The total storage required was about 24 MWords core memory and 18 MWords of SSD. I/O time was less than five percent of the total solution time.

Each operating point was typically run for 2,000 iterations. On the C-90 multiblock solutions required 7.42 seconds per iteration for $1,057,318$ points, or about $7.02 \times 10^{-6}$ seconds per iteration per grid point, and took about 4.1 hours per case.

Single block calculations were run on the C-90 eagle at NASA Ames, entirely in core. Single block solutions required 4.55 seconds per iteration for 748,374 points, or about $6.07 \times 10^{-6}$ seconds per iteration per grid point, and took about 2.5 hours per case.

\section{RESULTS}

Operating maps for the rotor at the design rotational speed were computed by running many cases with different back pressures. Choked flow points were run by imposing a low back pressure. They converged in about 1500 iterations. Intermediate flow points were computed by increasing the back pressure and restarting from a previous solution at a higher flow. Most intermediate points were run 2000 iterations. Near stall the back pressure was increased in very small increments. Cases were considered to be stalled if the flow rate and 


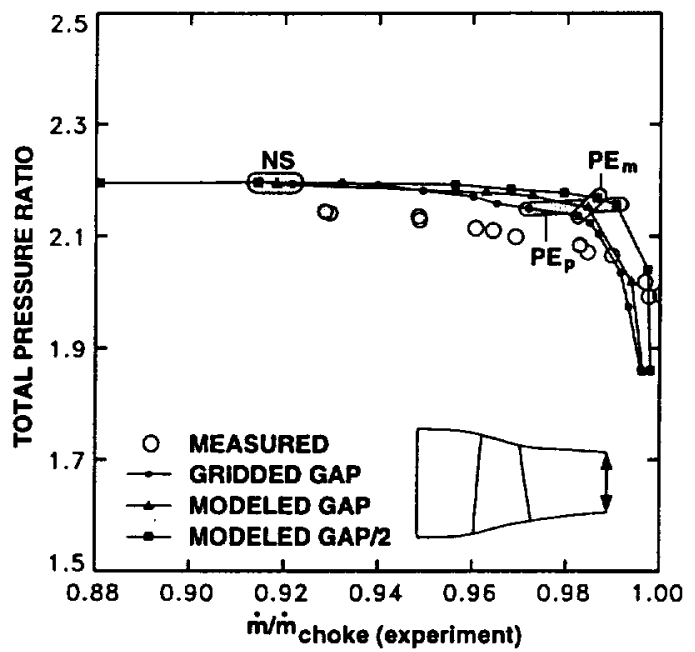

Fig. 3. Measured and computed pressure ratio characteristics.

integrated exit properties were still decreasing continuously after 8000 iterations. Three operating maps were computed. One was computed using the multiblock grid with a gridded clearance gap. The other two were computed using the single-block grid and the simple periodicity clearance model, one using the measured gap, and one using half the measured gap.

For the blind test case, calculated mass flows were normalized by the choking flow rate calculated by the respective code. Similarly, the experimental mass flows were normalized by the experimental choking flow rate. This procedure normalized all mass flows to one at choke, thereby hiding differences in the computed choking flow rates and distorting the relative shapes of the curves. To avoid confusion, all curves on a given plot should be normalized by the same value. Here the experimental choking flow rate was used to normalize all flow rates because it was given with the initial specifications of the blind test case. A computed value could have been used as well, but the best procedure is probably to leave the flow rate in dimensional terms.

The multiblock grid started 0.63 chords further upstream than the single block grid, and the multiblock solutions included endwall boundary layer losses and shock losses in that region. These losses were evaluated by averaging the multiblock solutions at the inlet of the single block grid. Then each single-block solution was adjusted to have the same corrected massflow and inlet total pressure as its respective multiblock solution.

Figure 3 compares characteristics of pressure ratio versus mass flow calculated with the three clearance models to experimental data. The calculations were energy-averaged over the entire exit grid, not at just the experimental spanwise measurement points as recommended for the blind test case. The experimental characteristic is not vertical at choke because the rotor-only tests (shown) choked prematurely in the facility diffuser. Tests of a complete stage choked in the rotor at the quoted flow rate [22]. Two of the computed characteristics are not perfectly vertical at choke because the extra operating points were not run. It is felt that these two curves are choked at their lowest points for all practical purposes.

The calculated pressure ratios are all higher than the experimental data. The multiblock results (dots) match the slope of the measured

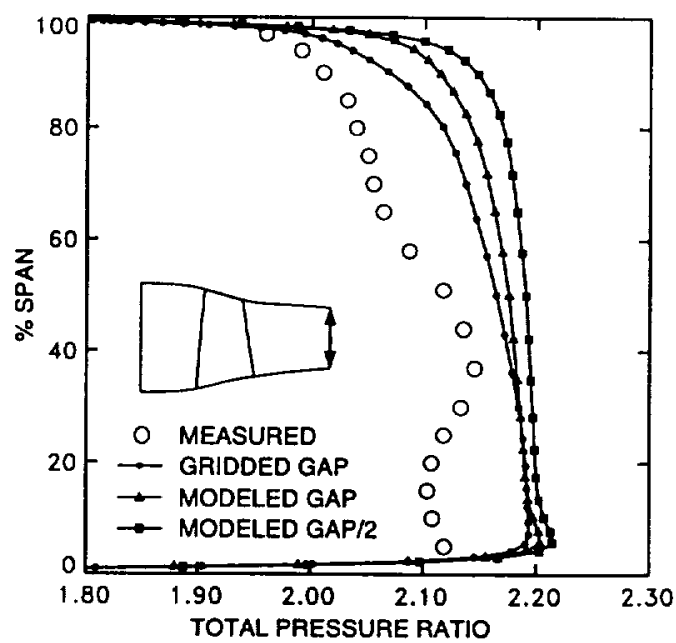

Fig. 4. Total pressure ratio profiles, station 4, peak $\eta$, calculations at same mass flow.

characteristic slightly better than the modeled gap results. Modeled-gap results using the full gap height (triangles) match the multiblock results closely. The half-gap model results (squares) have a very low stall point and show an abrupt fall-off to choke with a higher choking flow. The stall point was determined to four significant digits in back pressure for the multiblock calculations, but slightly less accurately for the singleblock calculations.

Spanwise profiles of pressure ratio or efficiency computed with the three clearance models are compared to probe data measured at station 4 at the nominal peak efficiency point in figures 4-6. Results are usually compared at a constant mass flow, found iteratively by varying the back pressure. Total pressure profiles at 98 percent flow (the three circled points labeled " $\mathrm{PE}_{\mathrm{m}}$ " and shaded experimental point in figure 3) are shown in figure 4 . All computed pressure ratios are higher than the data and fail to match the shape of the measured profile. This discrepancy was common to most of the codes entered in the blind test case and has yet to be explained. Profiles from the three models are very different over the entire span and not just at the tip as might be expected. This is because the three models required different back pressures to produce the same nominal mass flow, apparently because the models produce different amounts of endwall blockage. The exit hub static pressure ratio required for 98 percent flow was 1.225 for the gridded gap model, 1.24 for the full-gap model, and 1.25 for the half-gap model. Exit static pressure profiles (not shown) vary almost linearly from hub to tip, and the total pressure profiles vary in proportion to the static pressure.

The three models were also compared at a constant back pressure ratio of 1.24 (the three circled points labeled " $\mathrm{PE}_{\mathrm{p}}$ " in figure 3.) Although comparing results at constant back pressure is not standard practice, several arguments can be made for doing so.

1. Mathematically, back pressure is an independent variable while mass flow is a dependent variable. The results are mathematically similar if they have the same independent variables.

2. Physically, back pressure (throttle setting) is also an independent variable while mass flow is a dependent variable.

3. At choke, mass flow is constant and cannot be used to compare results. 


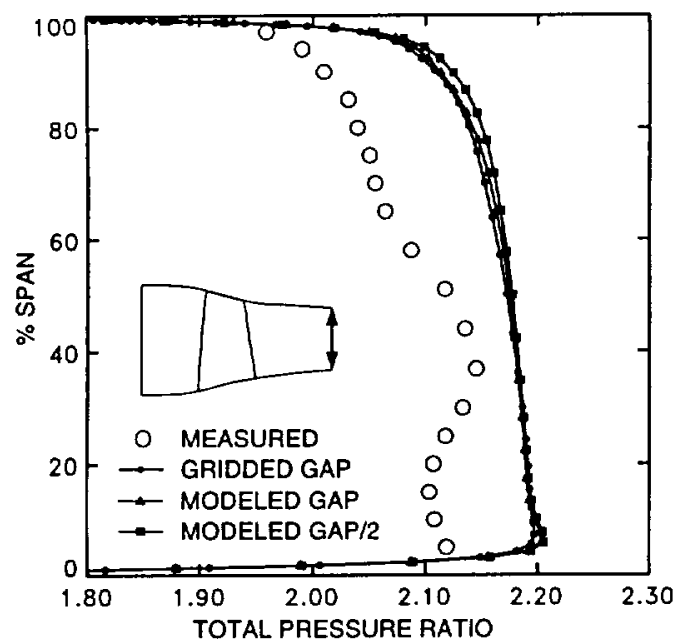

Fig. 5. Total pressure ratio profiles, station 4 , peak $\eta$, calculations at same back pressure.

4. In a two-dimensional blade element calculation, e. g., [8 or 22], mass flow is a meaningless quantity but back pressure can still be used to compare results.

At constant back pressure the total pressure profiles collapse neatly except near the tip, as shown in figure 5. It is felt that this comparison separates the effects of the clearance model from the effects of varying back pressure. Here total pressure distributions computed using the full-height modeled gap agree closely with the multiblock results, but total pressures computed using the half-height gap are somewhat high at the tip.

Adiabatic efficiency profiles at the same back pressure are shown in figure 6. All models are in fairly good agreement with the data except near the tip. The three models give nearly identical results up to about 70 percent span. Near the tip, the full-height modeled gap gives the better agreement with the multiblock results.

From the results shown in figures 3-6 it is concluded that the simple clearance model using the full gap height gives reasonable agreement with a more detailed multiblock model. Later discussion will suggest a physical explanation for this conclusion. However, the conclusion does contradict the work of Adamczyk et al. who found that using one-half the gap height gave the best match with the experimental stall point for a transonic fan [2]. The reasons for this disagreement are unknown.

The remaining results make some detailed comparisons between the multiblock computations and the experimental data near the tip to validate the multiblock code. The physics of the clearance flow is then discussed.

Results at an operating point near peak efficiency (highlighted point labeled "PE" in figure 3) are shown in figures 7-11. Computed and measured contours of normalized axial velocity (normalized by $\mathrm{U}_{\mathrm{tip}}=454.14 \mathrm{~m} / \mathrm{sec}$ ) at 95 percent span are compared in figure 7. Axial velocity contours are measurable, independent of frame of reference, and show many flow features surprisingly well. The contours show a shock standing ahead of the leading edge of each blade that runs obliquely downward to the suction side of the neighboring blade where it hits at about 70 percent chord. The tip vortex core leaves the leading edge of each blade and runs diagonally upward across the passage and

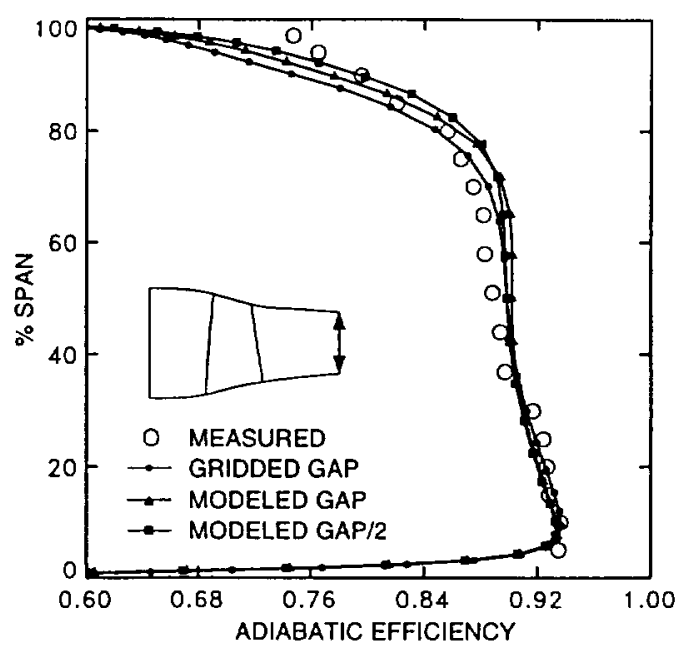

Fig. 6. Adiabatic efficiency profiles, station 4, peak $\eta$, calculations at same back pressure.

through the shock. Above the shock-vortex interaction is a region of low-momentum fluid with no evidence of a vortex in the contours. The computed contours match the measured contours quite well except in the low-momentum region near mid-chord, and in the wakes.

The path of the vortex core was estimated using the analytic model of Chen et al. [4] and is shown by the dashed line in the figure. This model maps the three-dimensional steady vortex trajectory problem to a two-dimensional unsteady vortex growth problem on a crosschannel plane. The model is inviscid and incompressible, neglects blade thickness, and assumes that the pressure difference across the clearance gap drives the flow. It shows that the center of the tip vortex should move linearly away from the blade with an angle of 16.7 degrees between the blade surface and the vortex core. Figure 7 shows an angle of about 17 degrees for computations and about 18 degrees for the measurements. The excellent agreement between the computations, measurements, and Chen's model tends to verify that the clearance vortex is driven by the pressure difference across the clearance gap.

Computed blade-to-blade profiles of relative Mach number at 95 percent span are compared to laser data at two axial locations in figures $8 \mathrm{a}$ and $8 \mathrm{~b}$. These figures help to quantify the more qualitative comparison made with the contour plots in figure 7 . Figure 8 a compares profiles at station 2, showing some disagreement in profile shape and shock location. At 95 percent span this profile is well within the casing boundary layer where the computations are probably strongly influenced by the turbulence model. Figure $8 \mathrm{~b}$ compares profiles at station 3, showing that the measured wake has mixed out more than the computed wake. Many of the codes entered in the blind test case failed to predict the measured wake mixing unless a highly-stretched grid was used downstream; then inadequate resolution of the wakes gave better agreement with the data. Other turbulence models do not appear to improve the wake predictions. In reference [8], quasi-three-dimensional calculations of this rotor with a $\mathrm{k}-\omega$ turbulence model gave wake profiles only marginally better than those calculated with the BaldwinLomax model. It is also possible that the rapid mixing of the measured wakes is due to unsteady vortex shedding not modeled with the steady calculations. 

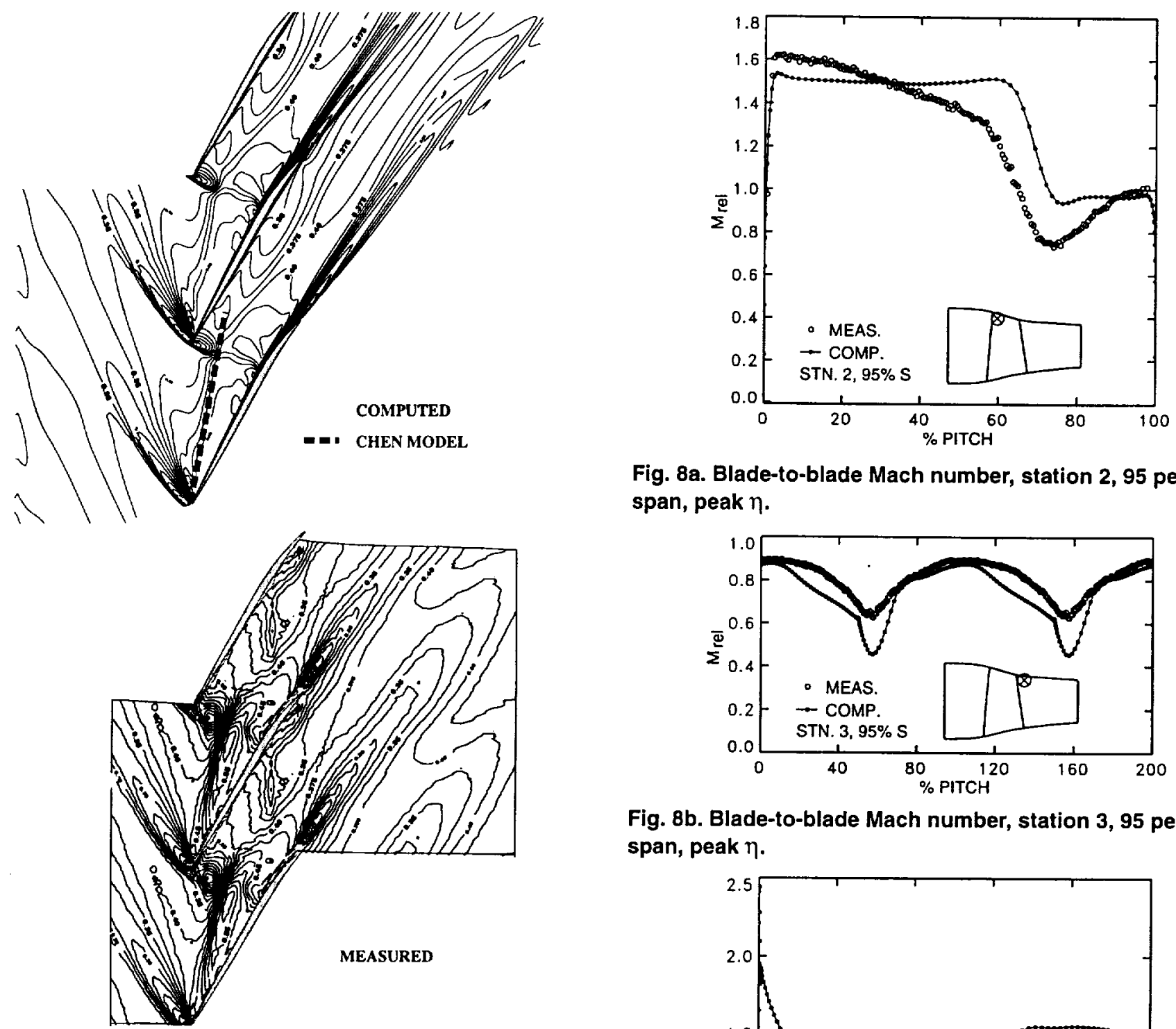

Fig. 7. Contours of normalized axial velocity component at 95 percent span, peak $\eta$.

Based on the relatively good agreement between the calculations, Chen's model, and the measurements shown in figures 7 and 8 it is concluded that the multiblock calculations are sufficiently accurate for investigating the interaction of the shock, the clearance flow, and the casing boundary layer. Figure 9 begins by showing the computed static pressure distribution along the blade at 95 percent span. Three regions with different blade loadings can be seen: a highly-loaded region near the leading edge, a moderately-loaded region ahead of the shock, and a lightly-loaded region downstream of the shock. In conjunction with figure 10 it will be shown that the clearance flow behaves differently in these three regions.

Figure 10 shows the interaction of the shock and clearance flow. The shock location is approximated by contours of $p / p_{0}=0.84$ $\left(M_{\text {rel }} \approx 1.35\right)$, shown at 95 percent span and at mid-gap. At 95 per-

Fig. 8a. Blade-to-blade Mach number, station 2, 95 percent span, peak $\eta$.

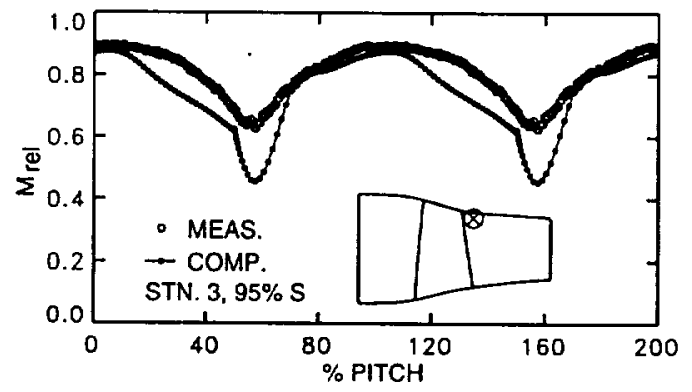

Fig. 8b. Blade-to-blade Mach number, station 3, 95 percent span, peak $\eta$.

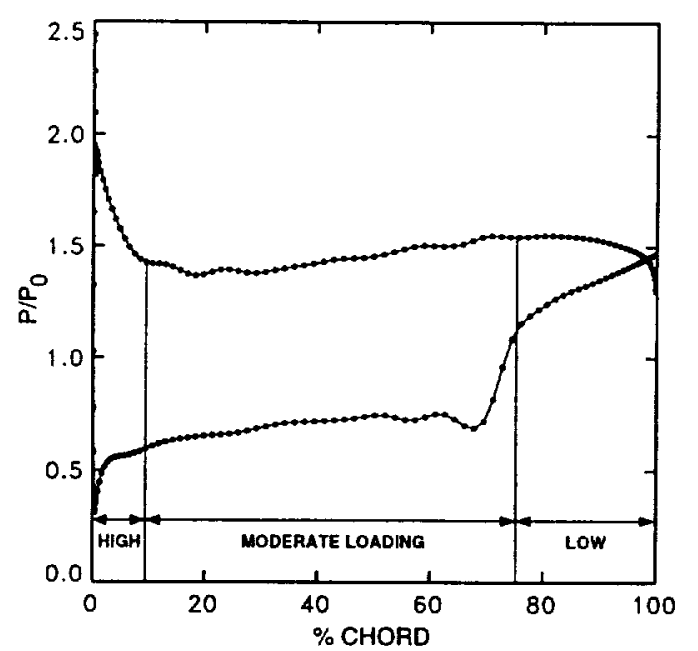

Fig. 9. Static pressure distribution at 95 percent span, peak $\eta$.

cent span the shock passes continuously across the passage. The shock at mid-gap bends where it intersects the clearance vortex. This phenomena will be discussed later. The clearance flow is shown by particle traces released at mid-gap and followed in both directions in timc. The clearance flow originates upstream of the blade within the endwall 


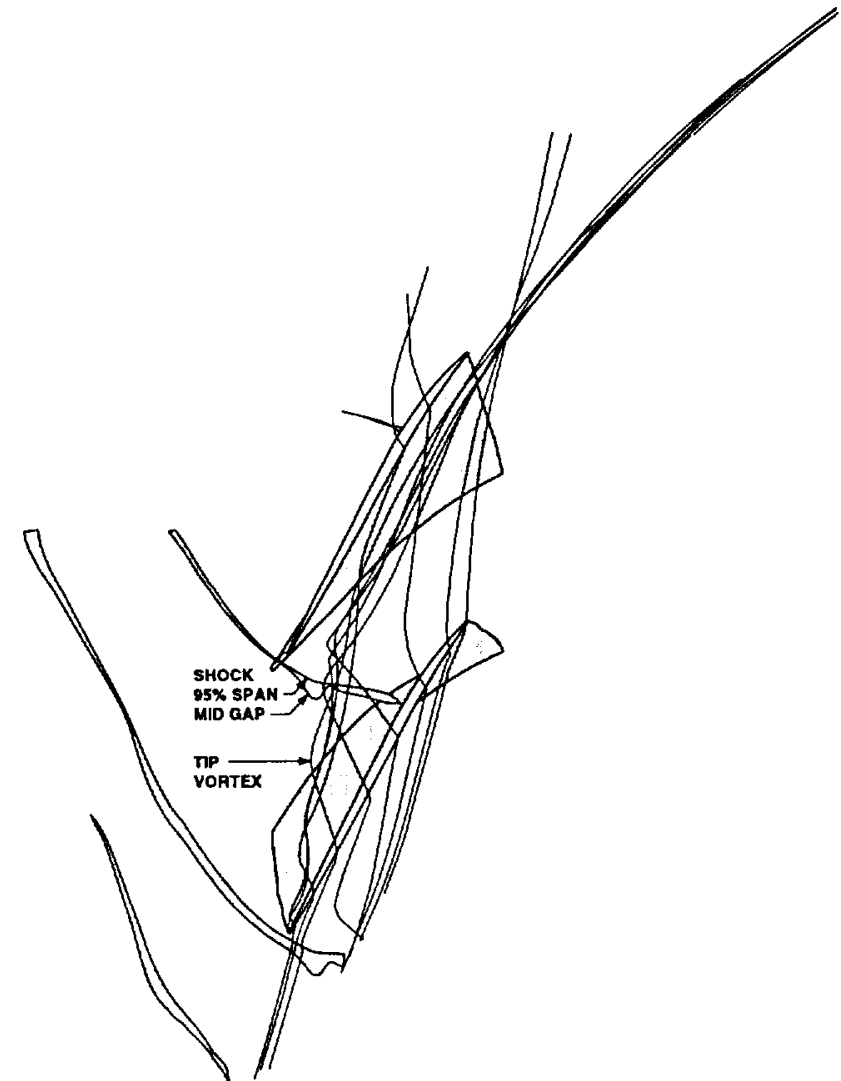

Fig. 10. Shock system above 95 percent span with tip particle traces, peak $\eta$.

boundary layer. It moves towards the pressure side of the advancing blade, climbs the blade surface, then turns abruptly around the edge of the blade and enters the gap. The clearance flow leaving the gap is discussed separately for the three regions of blade loading.

1. Highly-loaded region (less than about 10 percent chord.) Near the tip, the first 10 percent of the blade is highly loaded due to the high relative incidence of the casing boundary layer. The high loading generates a strong tip vortex that moves linearly across the passage and passes through the shock with no obvious change in direction or structure. Particles released in the highly-loaded region wrap several times around the vortex.

2. Moderately-loaded region (roughly 10 to 70 percent chord.) Between the highly-loaded region and the shock the blade is moderately loaded, with most of the loading coming from the shock. Particles leaving the gap in this region move along the casing in a thin wall jet that is highly skewed to the core flow. The wall jet moves upstream axially but downstream relative to the blade surface. When the particles reach the tip vortex they turn abruptly around it, drop down towards the core flow, and continue axially downstream without wrapping around the vortex again.

3. Lightly-loaded region (greater than about 70 percent chord.) Downstream of the shock the blade is lightly loaded. In this region the clearance flow is basically casing boundary layer flow that is mildly perturbed by the passing blades.

Figure 11 shows the effects of the shock and clearance flow on the casing boundary layer. A blade-to-blade plot of relative Mach number contours at the blade tip is shown at the right of the figure. This close to the casing the shock is highly smeared, and the tip vortex can be fol-

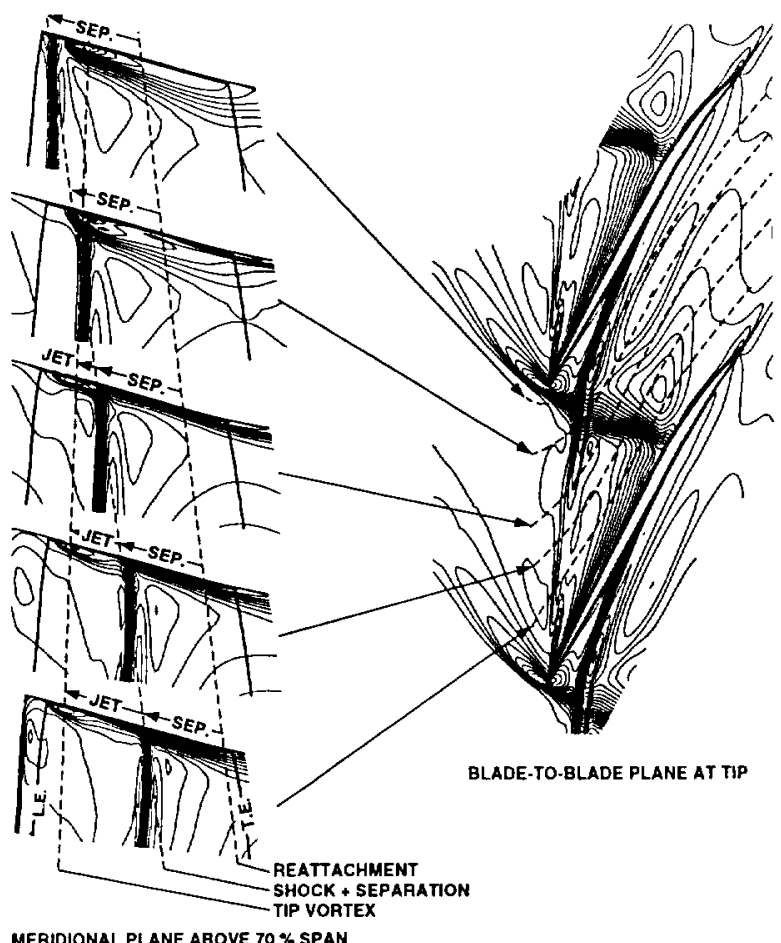

MERIDIONAL PLANE ABOVE $70 \%$ SPAN

Fig. 11. Mach number contours, peak $\eta$. Blade-to-blade plane at the tip, five meridional planes above 70 percent span.

lowed through the shock to the pressure side of the neighboring blade. Five meridional plots of relative Mach number contours above 70 percent span and at various tangential locations are shown at the left. The tangential locations are along the dashed $\mathrm{C}$-grid lines shown in the blade-to-blade view and are roughly equally-spaced blade-to-blade.

The bottom plot is near the suction side of the blade and shows the blade leading and trailing edges for reference. The upstream casing boundary layer is not evident at the far left, partly due to the limited extent of the plot but mostly because the relative Mach number of the casing is high. Plots of axial velocity indicate that the casing boundary layer is about 15 percent span high (half the height of the meridional plots) near the leading edge. The clearance vortex is evident just downstream of the leading edge, followed by a region of low-speed, wakelike flow. The shock is evident at about 60 percent chord, followed by an even larger region of low-speed flow caused by shock-boundary layer interaction.

Arrows above the blade tip indicate regions of reversed flow very near the casing, as determined from vector plots. As discussed previously, a wall jet moves upstream in the region between the shock and the vortex core. When the wall jet reaches the vortex core it turns around the vortex and back upstream, contributing to the shear layer downstream of the clearance vortex. The casing flow separates downstream of the shock and reattaches near the trailing edge.

The locations of the clearance vortex, wall jet, shock, separation, and reattachment are connected by vertical lines in plots moving up the page. The second plot from the top shows the location at which the shock and clearance vortex merge. Here the shock foot bifurcates into a lambda pattern over the vortex core, which was obvious in figure 10 as 

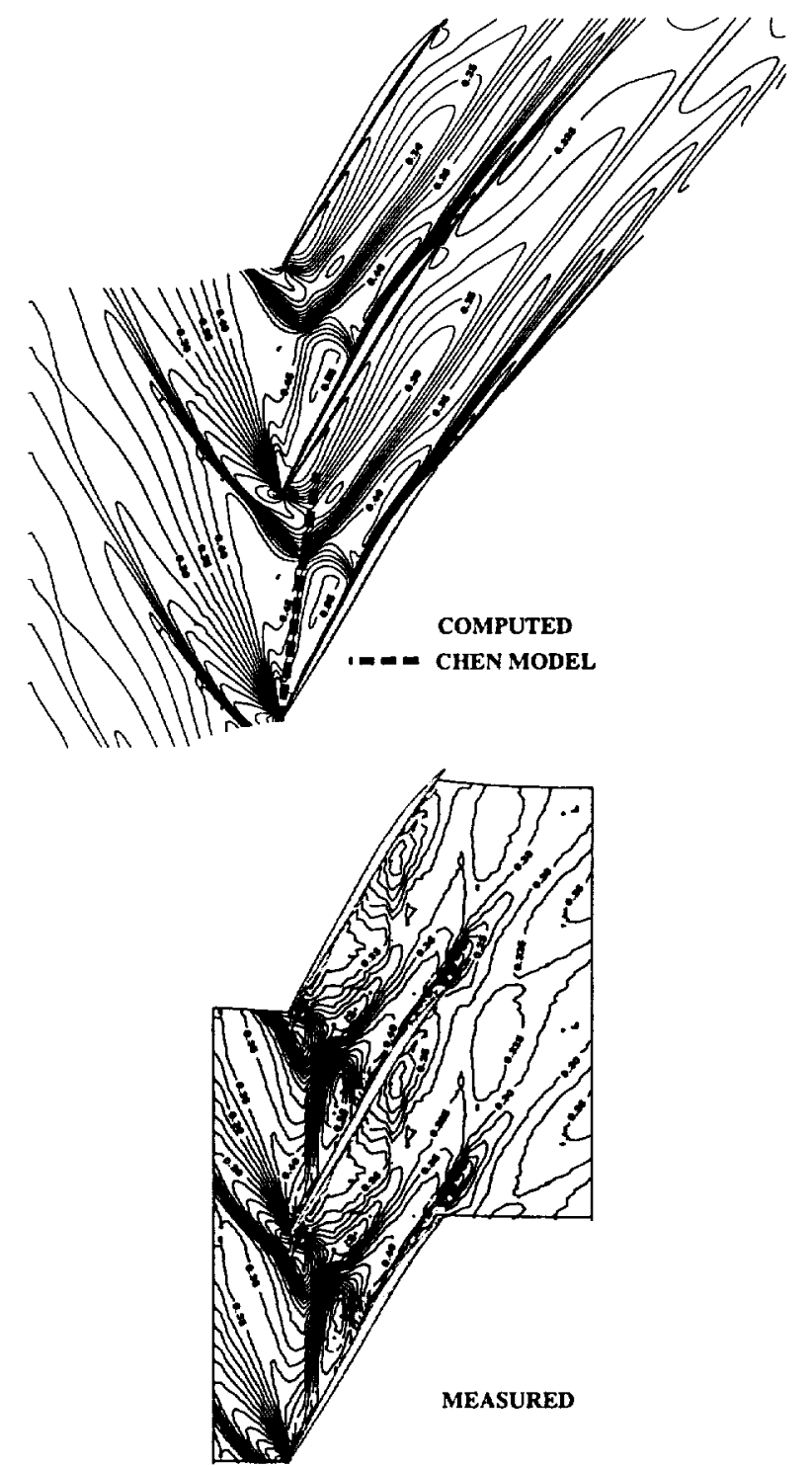

Fig. 12. Contours of normalized axial velocity component at 95 percent span, near stall.

the bend in the shock at mid-gap. The low-speed rotational flow following the shock flows over the vortex and produces a substantial wake. The top plot shows that the tip vortex is continuous through the shock. It is not clear if the vortex changes in size when passing through the shock.

Results at an operating point near stall (highlighted point labeled "NS" in figure 3) are shown in figures 12-16. In figure 12 computed and measured contours of normalized axial velocity at 95 percent span are compared. Near stall the shock stands further ahead of the blade and is stronger than at peak efficiency (figure 7.) The vortex trajectory estimated using the model of Chen et al. [4] is shown by the dashed line. Because the blade is more highly loaded than at peak efficiency, Chen's model gives a steeper angle of 18.8 degrees for the vortex trajectory. Figure 12 shows an angle of about 18 degrees for the computations and

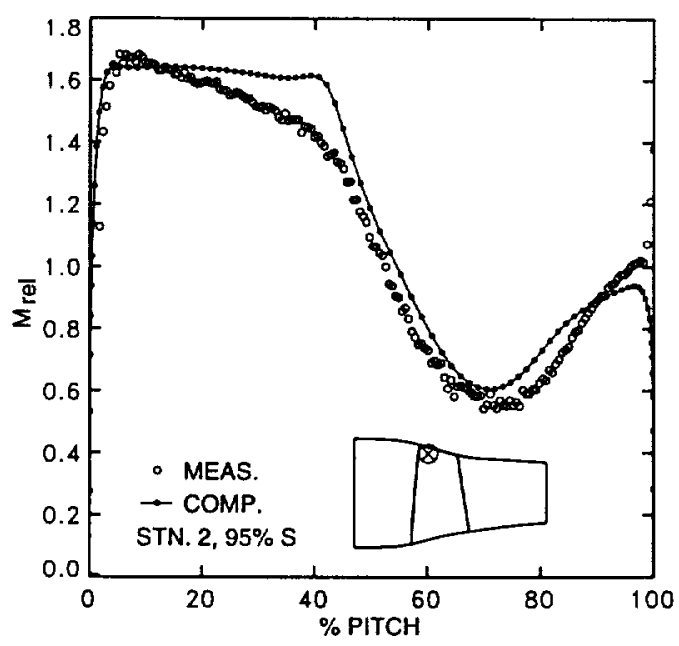

Fig. 13a. Blade-to-blade Mach number, station 2, 95 percent span, near stall.

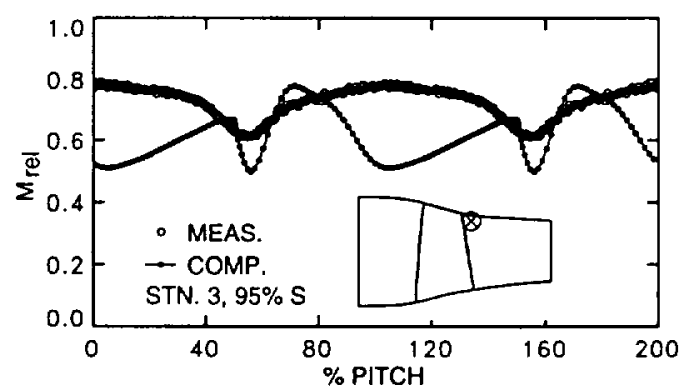

Fig. 13b. Blade-to-blade Mach number, station 3, 95 percent span, near stall.

about 20 degrees for the measurements, again in excellent agreement with the model. Since both the shock angle and vortex trajectory are steeper than at peak efficiency, the shock and clearance vortex meet closer to the center of the passage and a larger region of low-momentum fluid follows downstream. The computed contours match the measured contours fairly well except that the computed low-momentum region extends too far downstream, and again the computed wakes decay too slowly.

Computed blade-to-blade profiles of relative Mach number at 95 percent span are compared to laser data at two axial locations in figures $13 \mathrm{a}$ and $13 \mathrm{~b}$. Figure $13 \mathrm{a}$ compares profiles at station 2 , showing very good agreement between shock location and strength. In figure $13 \mathrm{~b}$ the laser data shows some wake remaining at station 3, but it is more mixed out than the computed wake. The computations show a large region of low-momentum flow at mid-passage that is not evident in the measurements. This low-momentum region will be related to the shock/clearance vortex interaction later.

Figure 14 shows the shock/clearance vortex interaction at the near-stall point. The shock stands much further ahead of the blade than at peak efficiency and intersects the suction surface further upstream. The shock at mid-gap bends where it intersects the clearance vortex. Again there are three regions of clearance flow: a strong tip vortex region, a wall jet region, and a region of perturbed casing boundary layer. The casing boundary layer separates behind the shock near mid- 


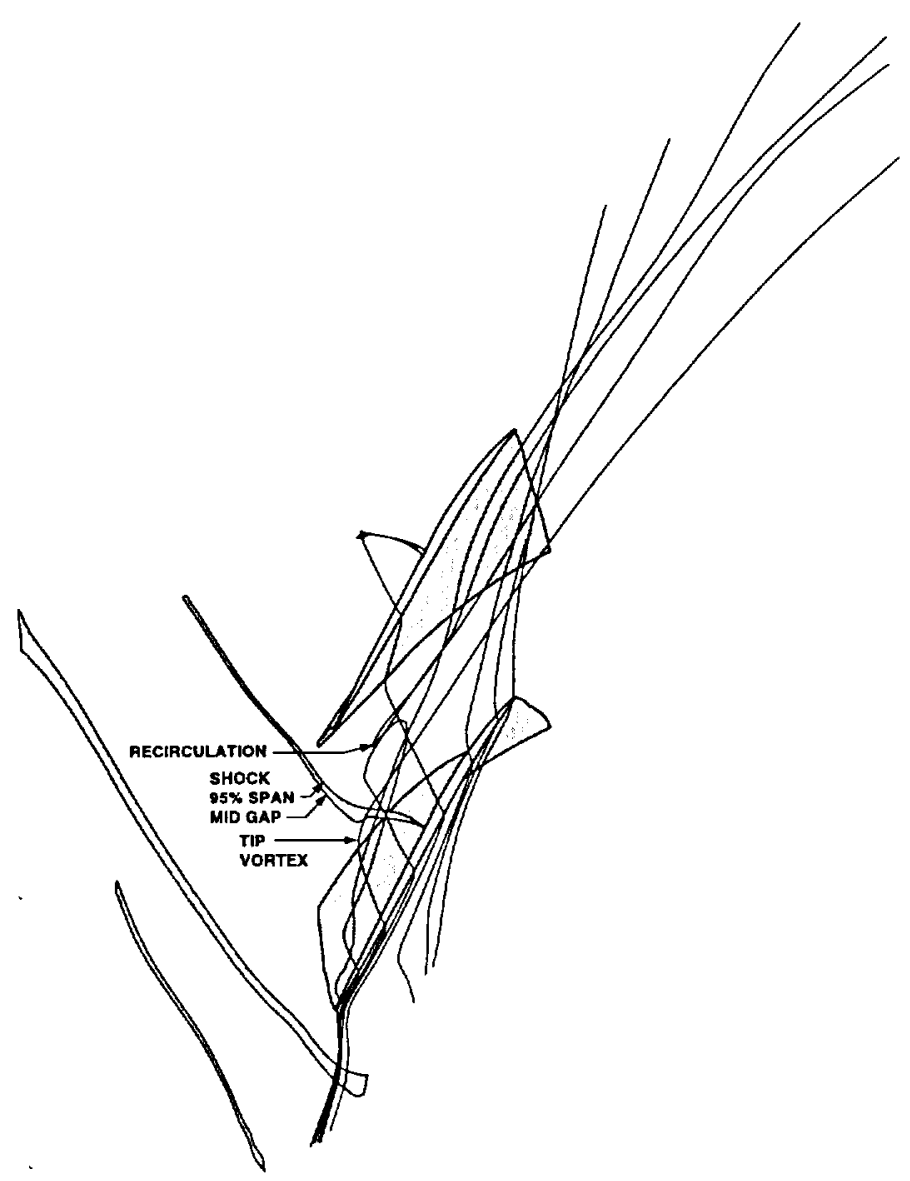

Fig. 14. Shock system above 95 percent span with tip particle traces, near stall.

passage, and some of the tip vortex flow is entrained in the separation bubble.

Figure 15 shows the effects of the shock and clearance flow on the casing boundary layer. A blade-to-blade plot of relative Mach number contours at the blade tip is shown at the right of the figure. Near stall the shock stand-off distance is much larger, the clearance vortex is stronger, and the bend in the shock is much more pronounced than at peak efficiency (figure 11).

Meridional plots of relative Mach number contours above 70 percent span and along the dashed C-grid lines shown in the blade-toblade view are shown at the left. The bottom two plots near the suction side of the blade resemble the plots at peak efficiency, except here the shock is further upstream and the wake-like region behind the tip vortex is stronger. In the middle plot the shock and vortex intersect, forming the lambda shock over the vortex that is visible in the blade-toblade view. The top three plots show a large recirculating region behind the shock-vortex interaction.

The clearance region includes a strong vortex followed by a wake, a wall jet flowing upstream, and shock-induced separation with reattachment. All of these phenomena are buried in a much deeper casing boundary layer. It is unlikely that the Baldwin-Lomax model can numerically determine a consistent length scale in this region. Moreover, it is unlikely that any algebraic turbulence model can adequately characterize the turbulence in this region with a single length scale. It is thus suspected that inadequacies in the casing turbulence model are responsible for the underprediction of tip efficiencies in figure 6 and the prediction of low-momentum clearance flow at 95 percent span in the near wake in figure $13 \mathrm{~b}$.

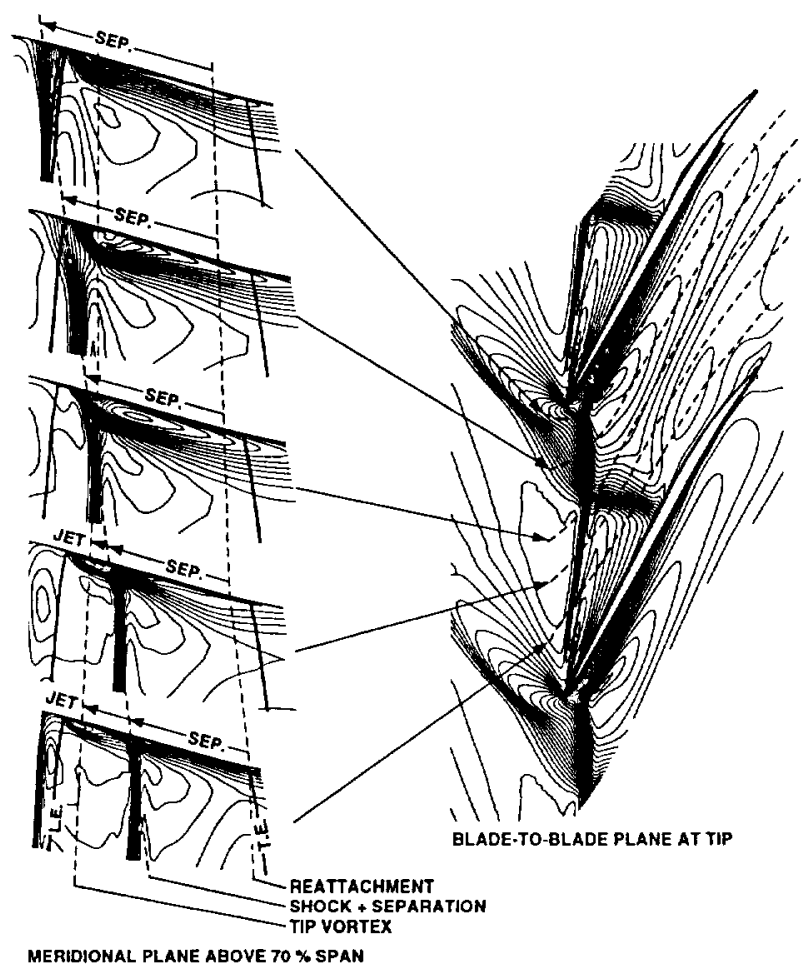

Fig. 15. Mach number contours, near stall. Blade-to-blade plane at the tip, five meridional planes above 70 percent span.

Relative Mach number contours near stall are shown on a crosssection at 10 percent of axial chord in figure 16 . At this location the tip vortex and shock-boundary layer interaction are distinct and can be seen near the casing. An enlargement of the tip clearance region is shown at the top of the figure. Here the clearance flow originates on the pressure side of the blade at $M_{r e l} \approx 0.8$, then accelerates around the corner of the blade through a Prandtl-Meyer expansion to $M_{r e l} \approx 1.3$, which is roughly the local tip Mach number. The flow accelerates gradually through the gap to $M_{\max } \approx 1.6$, which matches the suction-side Mach number of the core flow, as described by Storer and Cumpsty in [19]. The clearance flow is skewed about 50 degrees from the core flow (estimated from the particle traces in figure 15), and the shear layer between the two flows is obvious in figure 16. Several authors have suggested that the mixing of this shear layer causes most of the loss directly attributable to the clearance flow $[10,18$, and 19].

The clearance flow is supersonic in the regions of high and moderate blade loading (up to 70 percent chord.) In the lightly-loaded region the flow is subsonic and the computations show a thick boundary layer but no separation.

Figure 16 explains why the simple periodicity clearance model gives the best results using the exact gap height. Since the flow enters the gap through a supersonic expansion fan, there is no separation and the vena-contract model is inappropriate. Calculations by Ameri et al. [1] of a low-speed turbine rotor with a gridded clearance gap have shown the expected edge separation and reattachment. Based on these two calculations it is suggested that the simple periodicity clearance model should be used with the full gap height for blades with clearly supersonic tip speeds. For blades with square corners and subsonic tip speeds, a reduced gap height should probably be used. 


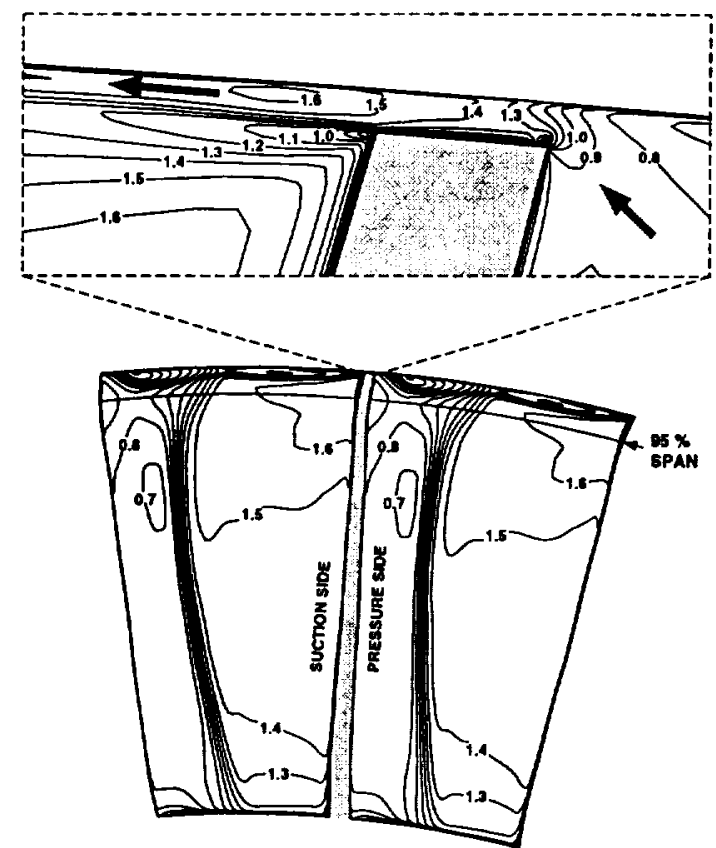

Fig. 16. Contours of $M_{\text {rel }}$ on a cross-section, 10 percent chord, near stall.

\section{CONCLUDING REMARKS}

Three-dimensional Navier-Stokes calculations were made of the tip clearance flow in a transonic compressor rotor. Tip clearance effects were modeled with a multiblock code by gridding the clearance flow and with a single-block code by using a simple periodicity model across the ungridded gap. The simple model was run with both the full gap height and with half the gap height to simulate a vena-contracta effect. Results were compared to aerodynamic probe data and to laser anemometer data. The following conclusions were drawn:

1. The simple clearance model gave good agreement with the multiblock calculations for performance predictions. The best agreement was obtained when the full gap height was used. The multiblock solution showed that the clearance flow entered the gap through a Prandtl-Meyer expansion with no vena-contracta or separation. This suggests that the simple periodicity clearance model should be used with the full gap height for blades with supersonic tip speeds, but probably with a reduced gap height for subsonic tip speeds.

2. The multiblock calculations agreed fairly well with the laser data at 95 percent span. The agreement was better at peak efficiency than near stall. The agreement was generally good up to the passage shock, but worse after the shock-clearance vortex interaction. This was probably a deficiency of the turbulence model. Computed wake profiles did not decay as quickly as the measured profiles. This may have been due to the turbulence model, but may also have been due to unsteady vortex shedding not modeled by the steady code. Although the computations did not match the data perfectly, it was felt that the results were sufficiently accurate to draw some qualitative conclusions regarding the physics of the clearance flow.

3. Three regions of varying blade loadings along the chord produced three regions of clearance flow with different behaviors. A small, highly-loaded region near the leading edge produced a strong clearance vortex. The vortex trajectory agreed very well with the laser measurements and the analytic clearance model of Chen et al. The vortex passed through the passage shock with little change in trajectory. It could not be determined if the vortex changed in size as it passed through the shock. A large, moderately-loaded region between the leading edge and the shock produced a wall jet. The wall jet moved upstream axially, turned abruptly around and under the tip vortex, and continued downstream without joining the tip vortex. A lightly-loaded region downstream of the shock passed the clearance flow with little effect.

4. Although the passage shock and clearance vortex are predominately inviscid phenomena, their impact on the casing flow was highly viscous. The tip vortex acted as an obstacle on the casing that extended across the passage and produced a wake-like structure along its entire length. The wall jet produced a shear layer where it left the clearance gap and another behind the tip vortex. The casing boundary layer separated along the entire length of the passage shock. A lambda shock formed at the shock-vortex intersection. A highly-rotational flow followed the shock-vortex interaction, with a large separated region at the operating point near stall. These phenomena were immersed in a much larger casing boundary layer, and strongly suggest the inadequacy of algebraic turbulence models in the clearance region. Many disagreements between the computations and data near the tip are probably due to the turbulence model, although the impact on overall performance predictions was not bad.

\section{REFERENCES}

1. Ameri, A. A., and Steinthorsson, E., "Prediction of Unshrouded Rotor Blade Tip Heat Transfer," ASME Paper 95 GT-142, 1995.

2. Adamczyk, J. J., Celestina, M. L., and Greitzer, E. M., "The Role of Tip Clearance in High-Speed Fan Stall," ASME $J$. Turbomachinery, Vol. 115, 1993, pp 28-38.

3. Baldwin, B. S., and Lomax, H., "Thin-Layer Approximation and Algebraic Model for Separated Turbulent Flows," AIAA Paper 78-257, Jan. 1978.

4. Chen, G. T., Greitzer, E. M., Tan, C., S., and Marble, F. E., "Similarity Analysis of Compressor Tip Clearance Flow Structure," ASME J. Turbomachinery, Vol. 113, April 1991, pp 260-271.

5. Chima, R. V., "Viscous Three-Dimensional Calculations of Transonic Fan Performance," in CFD Techniques for Propulsion Applications, AGARD Conference Proceedings No. CP510, AGARD, Neuilly-Sur-Seine, France, Feb. 1992, pp 21-1 to 21-19. Also NASA TM-103800.

6. Chima, R. V., Giel, P. W., and Boyle, R. J., "An Algebraic Turbulence Model for Three-Dimensional Viscous Flows," in Engineering Turbulence Modelling and Experiments 2, Rodi, W. and Martelli, F. editors, Elsevier pub. N. Y., 1993, pp. 775784. Also NASA TM-105931.

7. Chima, R. V., and Yokota, J. W., "Numerical Analysis of Three-Dimensional Viscous Flows in Turbomachinery," AIAA J., Vol. 28, No. 5, May 1990, pp. 798-806. 
8. Chima, R. V., "A k- $\omega$ Turbulence Model for QuasiThree-Dimensional Turbomachinery Flows," AIAA Paper 960248, Jan. 1996.

9. Dawes, W. N., "A Numerical Analysis of the ThreeDimensional Viscous Flow in a Transonic Compressor Rotor and Comparison With Experiment," ASME J. Turbomachinery, Vol. 109, 1987, pp 83-90.

10. Denton, J. D., "Loss Mechanisms in Turbomachines," ASME J. Turbomachinery, Vol. 115, 1993, pp 621-656.

11. Jameson, A., Schmidt, W., and Turkel, E., "Numerical Solutions of the Euler Equations by Finite Volume Methods Using Runge-Kutta Time-Stepping Schemes," AIAA Paper 811259, June 1981.

12. Kirtley, K. R., Beach, T. A., and Adamczyk, J. J., "Numerical Analysis of Secondary Flow in a Two-Stage Turbine," AIAA Paper 90-2356, 1990.

13. Kunz, R. F., and Lakshminarayana, B. "Explicit NavierStokes Computation of Cascade Flows Using the $\mathrm{k}-\varepsilon$ Turbulence Model," AIAA J., Vol. 30, No. 1, Jan. 1992, pp. 13-22.

14. Reid, L., Moore, R. D., "Design and Overall Performance of Four Highly-Loaded, High-Speed Inlet Stages for an Advanced, High-Pressure-Ratio Core Compressor," NASA TP1337, 1978.

15. Reid, L., Moore, R. D., "Experimental Study of Low Aspect Ratio Compressor Blading," ASME Paper 80-GT-6, Mar. 1980.

16. Smith, G. D. J., and Cumpsty, N. A., "Flow Phenomena in Compressor Casing Treatment," ASME J. Engr. for Gas Turbines and Power, Vol. 106, July 1984, pp. 532-541.

17. Sorenson, R. L. "A Computer Program to Generate TwoDimensional Grids About Airfoils and Other Shapes by Use of Poisson's Equation," NASA TM-81198, 1980.

18. Storer, J. A., and Cumpsty, N. A., "Tip Leakage Flow in Axial Compressors," ASME J. Turbomachinery, Vol. 113, April 1991, pp 252-259.

19. Storer, J. A., and Cumpsty, N. A., "An Approximate Analysis and Prediction Method for Tip Clearance Loss in Axial Compressors," ASME Paper 93-GT-140, May, 1993.

20. Strazisar, A. J., and Denton, J. D. "CFD Code Assessment in Turbomachinery - A Progress Report," IGTI Global Gas Turbine News, May/June 1995, pp 12-14.

21. Suder, K. L., and Celestina, M. L., "Experimental and Computational Investigation of the Tip Clearance Flow in a Transonic Axial Compressor Rotor," NASA TM-106711, 1994.

22. Suder, K. L., Chima, R. V., Strazisar, A. J., and Roberts, W. B., "The Effect of Adding Roughness and Thickness to a Transonic Axial Compressor Rotor," ASME J. Turbomachinery, Vol. 117, Oct. 1995, pp 491-505.

23. Wisler, D. C., "Loss Reduction in Axial Flow Compressors Through Low-Speed Model Testing," ASME J. Turbomachinery, Vol. 107, pp 354-363. 
Public reporting burden for this collection of information b estimated to average I hour per response, including the time for noviewing lnatructions, searching exlating data sources, gathering and maintaining the data needed, and completing and revlowing the collection of informalon. Send cormments regarding this burden estinale of any olhor aspect of ini Davis Highway. Sulte 1204, Arington, VA 22202-4302, and to the Office of Manapernent and Budget, Papenwork Reduction Propact (0704-0188). Washington, DC 20503.
1. AGENCY USE ONLY (Leave blank)
2. REPORT DATE
May 1996
3. REPORT TYPE AND DATES COVERED
Technical Memorandum

4. TITLE AND SUBTITLE

Calculation of Tip Clearance Effects in a Transonic Compressor Rotor

6. AUTHOR(S)

Rodrick V. Chima

7. PERFORMING ORGANIZATION NAME(S) AND ADDRESS(ES)

National Aeronautics and Space Administration

Lewis Research Center

Cleveland, Ohio 44135-3191

8. PERForiming ORGanization REPORT NUMBER

E-10242

9. SPONSORING/MONITORING AGENCY NAME(S) AND ADDRESSYES)

10. SPONSOAINGMONITORING AGENCY REPORT NUMBER

National Aeronautics and Space Administration

Washington, D.C. 20546-0001

NASA TM-107216

11. SUPPLEMENTARY NOTES

Prepared for the 41st Gas Turbine and Aeroengine Congress sponsored by the American Society of Mechanical Engineers Birmingham, United Kingdom, June 10-13, 1996. Responsible person, Rodrick V. Chima, organization code 2760, (216) 433-5919.

12a. DISTRIBUTIONAVAILABILTY STATEMENT

12b. DISTRIBUTION CODE

Unclassified - Unlimited

Subject Category 07

This publication is available from the NASA Center for AeroSpace Information, (301) 621-0390.

13. ABSTRACT (Max/mum 200 words)

The flow through the tip clearance region of a transonic compressor rotor (NASA rotor 37) was computed and compared to aerodynamic probe and laser anemometer data. Tip clearance effects were modeled both by gridding the clearance gap and by using a simple periodicity model across the ungridded gap. The simple model was run with both the full gap height, and with half the gap height to simulate a vena-contracta effect. Comparisons between computed and measured performance maps and downstream profiles were used to validate the models and to assess the effects of gap height on the simple clearance model. Recommendations were made concerning the use of the simple clearance model. Detailed comparisons were made between the gridded clearance gap solution and the laser anemometer data near the tip at two operating points. The computer results agreed fairly well with the data but overpredicted the extent of the casing separation and underpredicted the wake decay rate. The computations were then used to describe the interaction of the tip vortex, the passage shock, and the casing boundary layer.

14. SUBJECT TERMS

15. NUMBER OF PAGES

Turbomachinery; Compressor; Computational fluid dynamics; Tip clearance

\begin{tabular}{l|c}
\hline $\begin{array}{l}\text { 17. SECURTY CLASSIFICATION } \\
\text { OF REPORT } \\
\text { Unclassified }\end{array}$ & $\begin{array}{c}\text { 18. SECURTY CLASSIFICATION } \\
\text { OF THIS PAGE } \\
\text { Unclassified }\end{array}$ \\
\hline
\end{tabular}

19. SECURTY CLASSIFICATION OF ABSTRACT Unclassified 
National Aeronautics and

Space Administration

Lewis Research Center

21000 Brookpark Rd.

Cleveland, $\mathrm{OH}$ 44135-3191

Official Business

Penalty for Private Use $\$ 300$

POSTMASTER: If Undeliverable - Do Not Return 